\title{
МЕТОДОЛОГИЧЕСКИЕ ОСНОВЫ И ПРИНЦИПЫ АКТИВИЗАЦИИ ПОЗНАВАТЕЛЬНОЙ ДЕЯТЕЛЬНОСТИ УЧЕНИКОВ КАДЕТСКИХ КЛАССОВ НА УРОКАХ МАТЕМАТИКИ
}

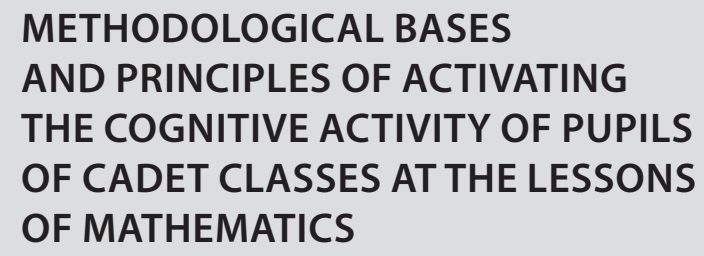

METHODOLOGICAL BASES

AND PRINCIPLES OF ACTIVATING

THE COGNITIVE ACTIVITY OF PUPILS

OF CADET CLASSES AT THE LESSONS OF MATHEMATICS

\section{Slonimskiy}

Summary: Purpose: Features of enhancing the cognitive activity of students of cadet classes in mathematics lessons and the methodological foundations used for this. Methods: the article uses a critical analysis of recent studies and publications on the problem under consideration, which contains not only a list of authors, but also the main conclusions of their work, their comparative analysis. Results: the use of various methods and principles contributes to the formation of independence, responsibility for the results of activities, creates conditions for effective self-realization of students, actualization of their individual abilities. Conclusions: in working with students of cadet classes, it is worth using such methodological foundations and principles of enhancing cognitive activity in mathematics lessons as: reducing lessons in the traditional form of teaching, differentiating the class into mobile groups; introduction of the principle of practical orientation of students with a high level of learning, to involve them in research activities, while students who are not interested in mathematics are motivated by applied sections and tasks; updating of methodological material.

Keywords: cadet class; activation of cognitive activity; methodological foundations; independence; self-realization.

\author{
Слонимский Денис Львович \\ Аспирант, Московский городской педагогический \\ университет \\ sdlv2204@gmail.com
}

Аннотация: Цель: Особенности активизации познавательной деятельности учеников кадетских классов на уроках математики и методические основы, применяемые для этого. Методы: В статье используется критический анализ последних исследований и публикаций по рассматриваемой проблеме, который содержит не только перечень авторов, но и основные выводы их работ, их сравнительный анализ. Результаты: использование различных методов и принципов способствует формированию самостоятельности, ответственности за результаты деятельности, создает условия эффективной самореализации учащихся, актуализации их индивидуальных способностей. Выводы: в работе со студентами кадетских классов стоит использовать такие методологические основы и принципы активизации познавательной деятельности на уроках математики как: сокращение уроков по традиционной форме обучения, дифференциация класса на мобильные группы; внедрение принципа практической ориентации учащихся с высоким уровнем обучаемости, задействовать их в исследовательской деятельности, при этом учащихся, кто не интересуется математикой, мотивировать прикладными разделами и задачами; обновление методического материала.

Ключевые слова: кадетский класс; активизация познавательной деятельности; методические основы; самостоятельность; самореализация.

щего поколения, в связи с этим появилось большое количество методик и программ образования. Кадетские школы прочно заняли свою нишу в профессиональном обучении подрастающего поколения, объединив в себе историческое наследие военного образования и современные методики воспитания и обучения. Подобные образовательные учреждения действуют только на основании соответствующего распоряжения.

Приоритетными задачами кадетских школ являются воспитание патриотизма и высокого чувства морали, долга, обучение военному делу, развитие личности во всех направлениях, не только на интеллектуальном уровне, но и на физическом [7].

Но все же в последнее время ученые уделяют все больше внимания повышению уровня познавательной 
активности учащихся, который, безусловно, обеспечивает рациональность мышления; готовность ставить и решать исследовательские задачи; усиление мобильности знаний.

Наша современная действительность характеризуется всесторонне проникновением математики в разные сферы человеческой жизнедеятельности. Она представляет собой мощный аппарат, который способствует развитию логического мышления учеников. Владение математическими методами, знание их особого языка становится обязательным элементом общечеловеческой культуры. Практические умения и навыки математического характера необходимы для дальнейшей трудовой и профессиональной подготовки учащихся.

Одним из ключевых аспектов деятельности учителя является усовершенствование, систематизация учебного процесса, побуждение учеников к сознательному и самостоятельному приобретению знаний, умений и навыков. Потому целью данной работы стало изучение особенностей активизации познавательной деятельности учеников кадетских классов на уроках математики и методические основы, применяемые для этого.

\section{Материалы и методы}

В статье использован анализ научных источников для освещения проблемы исследования, для выделения методических основ и принципов повышения и активизации познавательной деятельности учеников кадетских классов на уроках математики. Был произведен критический анализ последних исследований и публикаций, который содержит не только перечень авторов, но и основные выводы их работ, их сравнительный анализ.

\section{^итературный обзор}

Растущая роль математики в решении задач научнотехнического прогресса ставит перед школой задачу эффективной помощи учащимся в овладении учебным материалом и присущим этому предмету стилем мышления, является важным компонентом общей культуры современного человека.

Основная задача обучения математики в школе крепкое овладения учащимися системой математических знаний и умений, необходимых в повседневной жизни и трудовой деятельности каждому члену современного общества, достаточных для изучения современных дисциплин и продолжения образования. В последний время большое внимание уделяется повышению эффективности процесса обучения в школе, поскольку традиционная организация не отвечает требованиям времени, не создает условий для улучшения качества обучения и развития учащихся.
Для достижения лучших результатов в обучении необходимо выполнение следующих условий:

- формировать у ученика положительное отношение к учебе;

- подача учебного материала должна быть в определенной логические последовательности;

- демонстрация и закрепление учебного материала должно сопровождаться применением различных методов и приемов, которые активизируют умственную и творческую деятельность учащихся с учетом и возрастных особенностей;

- обязательное использование и закрепление знаний на практике.

Также для активизации познавательной деятельности учащихся, развития их мышления нужно использовать задачи, которые демонстрируют связь математики с жизнью. Примером таких задач является задачи с параметрами. Привлечение их к учебному процессу позволяет естественно и педагогически целесообразно имитировать полный процесс прикладного математического исследования или отдельных его этапов, что способствует развитию у учащихся глубокого устойчивого интереса к исследованию.

Также при изучении теоретического материала активизировать умственную деятельность помогает продуманная система вопросов, которая позволяет направлять мысли учеников в правильном русле, сделать их активными участниками беседы и направить их рассуждения для открытия чего-то нового, неизвестного. Большую роль играет введение инновационных технологий, которые способствуют развитию мышления учеников умение выслушать товарища и сделать свои выводы, учиться уважать мнение другого и уметь аргументировать собственное мнение.

ЗА Фридрих Диствергом - выдающимся педагогомдемократом, любой метод плох, если приучает ученика к пассивности, и хорош, если пробуждает в нем самодеятельность [4]. Каким бы хорошим и методично правильным ни было изложение самого учебного материала учителем, он не гарантирует успешного усвоения учащимися новых знаний. Усвоение происходит только тогда, когда ученик собственными усилиями, своей работой своего ума, воли, заставить себя слушать, понимать, запоминать. Поэтому учебно-познавательная деятельность учеников является и средством и в то же время результатом обучения. Потому необходимость активизации учебно-познавательной деятельности учащихся очень велика. Если ее не будет, то ни состоится и полноценного процесса обучения.

\section{Результаты}

Дифференцированная форма система обучения об- 
ращает внимание такие индивидуальные особенности учащегося, как обучаемость, учебные умения, познавательные интересы. В зависимости от индивидуальных особенностей, совокупность которых влияет на качество обучения школьников, особенностей поведения на математике, школьников разделяют на условные группы.

В соответствии с учетом всех особенностей можно выделить базовую группу школьников, группа прикладного уровня и повышенный уровень школьников. Разделение на уровне возможно проводить в разных формах. Основным вариантом разделения учащихся является формирование мобильных групп. Одним из важных критериев отнесения в группу является достижение базового уровня знаний по предмету. Дифференцированный подход не должен ограничивать самостоятельное обучение учащихся, использовать вариативный характер работы в группах в зависимости от сложности материала темы и помощи преподавателя.

Дифференцированный подход позволяет делать работу преподавателя целенаправленной, дает четкие ориентиры. Работа в группах позволяет более четко сфокусироваться на задачах, приведем пример такого разделения.

Ученики базовой группы должны понять содержание урока, темы, решить основные задачи по теме, понять для чего необходимо изучение данной темы. Главной задачей для школьников этой группы станет научиться решать основные виды типовых задач по обозначенной теме.

Ученикам в прикладной группе необходимо освоить все задачи, поставленные перед базовой группой, а также рассмотреть вопросы, где и как еще можно применить изучаемый материал. Учащиеся в этой группе решают прикладные задачи по обозначенной теме.

К учащимся творческо-исследовательской группы применимы повышенные требования они должны выполнить задачи предыдущих групп, кроме того, рассмотреть решение задачи исследовательского характера. Творческо-исследовательская группа изучает темы опережающими темпами, на несколько уроков вперед, выполняют задачи самостоятельно. Учащиеся составляют план изучения темы и самостоятельно анализируют содержание заданий, категорируя их на основные, усложненные, прикладные, логические. Выполняют все задания, предназначенные для классной и домашней работы. Учащиеся выявляют прикладной характер темы, самостоятельно подготавливают дополнительный материал по заданной теме. Школьники формируют раздаточный, дидактический и прикладной материал, готовят итоговый доклад по каждой изученной теме. В свою очередь в этой группе можно провести дополнительное деление на тех, кто предпочитает решать задачи, классифицируют его по уровням сложности. Другие любят разбираться информации, после изучения способов решения основных задач находят новое по теме - задачи прикладного характера, дополнительную информацию [5].

Таким образом реализовывается индивидуальный подход в образовательном процессе. Индивидуальные консультации позволяют разобраться в теме каждому, обеспечить более высокую успеваемость и качественную математическую подготовку. Реализовывается принцип практической ориентации, учащиеся с высоким уровнем обучаемости будут задействованы в исследовательской деятельности, учащиеся не интересующиеся математикой, но любители естественнонаучных дисциплин, обретут смысл изучения предмета.

Индивидуальный аспект изучения реализовывается в построении школьных программ, проектировании процесса обучения. Все это можно отнести к составляющим дидактического треугольника.

При подготовке изучению раздела математики преподаватель должен понимать минимально-требуемый уровень знаний, в каком ракурсе преподнести дополнительную информацию для прогрессивных учеников.

Для реализации такого подхода требуется обновление методической базы. Необходимо подготовка специальных карточек для самостоятельных и практических работ учащихся. В зависимости от уровня подготовки в карточки включаются соответствующие задания, практические работы, требующие также самостоятельного изучения вопроса. Задания могут содержать пропущенные данные с целью внесение данных вручную с учетом способностей каждого ученика. Предлагаемая домашняя работа должна соответствовать уровню каждого обучающегося, составлена с учетом его способностей. Основное требование, что время, потраченное на выполнение домашнего задания для всех должно быть примерно одинаковым.

Школьник должен иметь доступ к предыдущему материалу в момент изучения новой темы. Должна быть обеспечена возможность повторить ранее пройденный материал. Для этого можно использовать учебник, иную литературу, буклеты, электронные ресурсы. Также урок должен включать дифференцированный подход.

Математическая подготовка уроков должна включать разноплановую подготовку. Карточка для каждого школьника должна быть составлена с учетом способностей и индивидуальных особенностей содержать разноуровневые задания, в которых он допустил ошибки, дополнительные заданиями направленные на усвоение сделанной ошибки. Компьютерные программы могут 
стать альтернативным вариантом таких карточек. По итогам контрольной работы, завершения коррекционной работы учителю необходимо подготовить контрольную работу с вариативными ответами с целью погружения школьника в иную ситуацию.

Кадетские учреждения - сегодня это ответ на вызов общества с новыми социокультурными задачами, отвечающие новому типу образовательного учреждения.

Формирование мотивации изучения математики ставит перед учителем непростую задачу, раскрыть красоту математики и отразить ее прикладную обоснованность, учитель должен заинтересовать всех учеников в классе. Особая роль отводится решению прикладных, практических задач.

Эффективность индивидуального обучения определяется точностью поставленных задач, их конкретизацией, выявление способностей каждого из учеников, а также определения уровня развития школьника, его личных качеств, а также от профессионализма самого учителя, уровня его профессиональной подготовки. Учитель должен уметь применять знания на практике, демонстрировать прикладной характер знаний [6].

Основные организационно-методические условия реализации принципов дифференциации и индивидуализации:

- сокращение уроков по традиционной форме обучения, дифференциация класса на мобильные группы;

- внедрение принципа практической ориентации учащихся с высоким уровнем обучаемости, задействовать их в исследовательской деятельности, при этом учащихся, кто не интересуется математикой, мотивировать прикладными разделами и задачами;

- обновление методического материала.

Одним из методов обеспечения вовлеченности в процесс обучения является использование исторических сведений и литературных сюжетов в процессе урока. Общая черта учебной литературы - стремление преподнести значимость науки с включением исторических справок.

В качестве мотивации на уроках используют анимации, короткометражные видео, клипы, элементов исследовательских работ. Уроки организовывают в виде семинаров, дискуссий, проводят школьные олимпиады и другие математические соревнования, и конкурсы.

Учитывая специфику кадетских учреждений графические примеры необходимо рассматривать на примере строительства, физических и химических процессов, информационных технологий.
В качестве тем исследовательских работ желательно предлагать темы, связанные с практическим применением, презентацию работы можно проводить в электронном формате.

Элементы игр и соревнований вносят свой вклад в мотивацию при изучении математики, различные системы рейтинговая способствуют:

- стремиться к новым знаниям, не останавливаться на достигнутом, побеждать в олимпиадах, подготавливать новые исследовательские работы;

- давать уверенность ученикам со средними знаниями по дисциплине, поощрять их достижения;

- в целом выстаивать систему поощрения школьников.

Для формирования мотивации школьник должен иметь не только интерес к предмету, но и осязаемый результат, который позволяет ему осмыслить происходящее и быть заинтересованным в получении более высоких оценок.

На основании исследование психологических особенностей мальчиков, можно сформировать методические рекомендации по организации учебного процесса у кадетов:

- изучение нового раздела начинается с закрепление ранее пройденного материала;

- давать возможность мальчикам самостоятельно формулировать правила, гипотезы, теоремы, давать задания на логику;

- использовать методы мозгового штурма, эвристические методы, активно задействовать школьников в процессе обучения, обсуждать предлагаемые идеи;

- материал должен сопровождаться визуальным рядом;

- проводить на уроках моделирование ситуации, строить динамические модели ситуации, в том числе военных действий;

- для физической разрядки использовать активные физические игры, перемещения по учебному классу;

- наиболее подвижным ученикам подготавливать индивидуальные задания;

- поддерживать соревновательный дух среди школьников, внедрять рейтингование, давать карточки разного цвета, обозначающие уровень выполнения задания или наклейки для тетради, присваивать баллы, для старшеклассников оформлять портфолио

- в течении урока расставлять эмоциональные акценты;

- похвала за достижения должна быть краткой и обоснованной, отрицательная характеристика должна быть также краткой и четкой; 
- нивелировать влияние негативных лидеров в классе, поощрять мальчиков, находящихся на нижних ступенях неофициальной иерархии;

- давать возможность выразить знания письменно, визуально, с помощью компьютерных программ, использовать невербальные языки.

Обучение математики является всесторонним в кадетском классе. Уровень преподавания зависит от профессионального уровня учителя. Индивидуальный подход в обучении основывается на определении индивидуальных особенностей с построением в последующем индивидуальных задач для каждого школьника. Обращая внимание на особенности обучения мальчиков, грамотным подходом в обучении можно добиться уважения и признания с их стороны, а также положительной динамики успеваемости [9].

\section{Обсужмение}

Структура языка математики отличается от структуры других языков, но, как и любая система имеет схожую основу - лексика естественного языка является основой для любого искусственного. Математический язык состоит из элементов естественного языка, графиков, фигур, постепенно отдаляется в сторону формализации. Так как каждому уровню учащихся соответствует свой математический язык, использовать в учебном процессе его нужно дозированно, соблюдая ограниченность использования формализированных средств языка.

Низка способность к абстрактному мышлению является проблемой при изучении математического языка. Математическая семантика неотделима от математического языка и требует совместного изучения, сопряженного с изучением естественного языка.

Развитию общеязыковой культуры учащихся способствует изучение математического языка в совокупности с естественным языком. Так изучение отдельных математических символов, работа над формами, суждениями, как следствие работа над единицами языка - словами, словосочетаниями, предложениями реализует математическое мышление и математический язык в рамках общеязыковой культуры. Эта взаимосвязь обеспечивает усвоение материала и отражается на запоминании новых знаний.

Математическая наука рассматривается как единое целое, как цель профессионального образования учащихся. Культурологический подход в качестве социологического аспекта выделает тот факт, что рассмотрение математической культуры как исторического явления, связанного с развитием познания и сознания.

Ядро теории по математике составляют теоремы, требующие доказательств. По мнению Л.В. Ворониной, проводится логический анализ и математический анализ, который раскрывает математическое содержание элементов структуры. При выстраивании доказательной базы теоремы, учащийся работает с логической цепочкой аргументов. Такой подход формирует особенный склад ума, который основывается на формально-логических взаимосвязях. Выражение мыслей становится лаконичным, аргументированным, четким, понятен ход мышления учащегося [3].

Рассматривая проблему формирования мотивации у детей к изучению математики в кадетских классах, можно утверждать, что формирование мотивов, связанных с содержанием учебно-познавательной деятельности, обеспечивается деятельностью учителя, направленной на то, чтобы, с одной стороны заинтересовать кадетов красотой математики, с другой стороны продемонстрировать необходимость ее изучения.

Во-первых, особую актуальность приобретает использование в учебном процессе практико-ориентированных, прикладных, старинных задач.

Во-вторых, один из методов заинтересовать учащихся является использование исторических сведений и литературных сюжетов в процессе урока [8].

В-третьих, развитию мотивов, связанных с процессом обучения, способствует применение в учебном процессе ИКТ (анимаций, короткометражных видео, музыкальных клипов), элементов исследовательской деятельности, учебные занятия в виде научных семинаров, дискуссий, школьные олимпиады и другие математические соревнования, и конкурсы [1].

В кадетских учреждениях основываясь на специфике кадетам полезно рассматривать анимации, связанные со строительством, с информационными технологиями, с физическими и химическими процессами.

В-четвертых, что касается исследовательской деятельности, полезно предлагать ученикам темы на научную конференцию связанные с практической деятельностью, презентовать работу можно в форме сайта.

В-пятых, рейтинговые или накопительные технологии в школе вносят в процесс обучения математике элементы игры и соревнования. Для формирования высокой мотивации образования, учащийся должен иметь сформированный познавательный интерес, помимо этого, получаемый результат от обучения придаст личностный смысл образовательному процессу [2].

\section{Зак^ючение}

Кадетское образование прежде всего развивает 
чувство патриотизма, чувства долга и ответственности, формируются духовно-нравственные основы личности. По мнению В.И. Андреева, «без воспитания российского патриотизма у подрастающего поколения ни в экономике, ни в культуре, ни в образовании мы не сможем уверенно двигаться вперед, так как наше будущее должно иметь свою духовно - нравственную основу, свой духовно - нравственный стержень - любовь к Отечеству, к своей Родине».

В работе со студентами кадетских классов стоит использовать такие методологические основы и принципы активизации познавательной деятельности на уроках математики как: сокращение уроков по традиционной форме обучения, дифференциация класса на мобильные группы; внедрение принципа практической ориентации учащихся с высоким уровнем обучаемости, задействовать их в исследовательской деятельности, при этом учащихся, кто не интересуется математикой, мотивировать прикладными разделами и задачами; обновление методического материала.

При грамотном подходе учителя на уроке математики образование в кадетском корпусе дает всесторонние развитие личностных способностей учащихся, что является индивидуальным подходом.

\section{ЛИТЕРАТУРА}

1. Балашова 0.Ю. Манушкина М.М. Особенности формирования мотивации к изучению математики у студента технического вуза // Материалы всероссийской заочной научно-практической конференции с международным участием «Современный учебно- воспитательный процесс: теория и практика»; г. Красноярск, 2019 г. С. $91-96$.

2. Балашова 0.Ю. Манушкина М.М. Особенности формирования мотивации к изучению математики у студента технического вуза // Материалы всероссийской заочной научно-практической конференции с международным участием «Современный учебно- воспитательный процесс: теория и практика»; г. Красноярск, 2019 г. С. $91-96$.

3. Блинова Т.Л. Реализация уровневой дифференциации посредством сочетания методов решения геометрических задач образование и наука в современных условиях // Чебоксары: Общество с ограниченной ответственностью «Центр научного сотрудничества «Интерактив плюс». 2015. №3. С.54-56.

4. Дистервег А. Избранные педагогические сочинения. М.: Учпедгиз, 1956. — С. 136-203.

5. Мельникова Н.Б. Контрольные работы по геометрии. 7 класс. К учебнику Л.С. Атанасяна и др. «Геометрия. 7-9 классы». ФГОС. М.: Экзамен. 2016. - С. 112

6. Насыпаная В.А. Особенности формирования у школьников математической культуры В современных условиях / В.А. Насыпаная. - Текст: непосредственный, электронный // Педагогическое мастерство: материалы Х Междунар. науч. конф. (г. Москва, июнь 2017 г.). — Москва: Буки-Веди, 2017. — С. 78-80. — URL: https://moluch.ru/conf/ped/archive/215/12424 (дата обращения: 06.09.2021).

7. Основы Концепции и Государственного стандарта кадетского образования в России. Сайт московские суворовцы. [Электронный ресурс]. URL: https:// mccvu.ru/ads/kontseptsiya-kadetskogo-obrazovaniya/ (Дата обращения 07.09.2021)

8. Прохорович М.А. Курьезы и юмор с физико-математическим уклоном. Пущино: 000 «Фотон век», 2015. С.152

9. Самохин В.Ф., Ланских Е.А. Пропедевтика военной службы в кадетских классах средних общеобразовательных школ: сущность и педагогические условия реализации// Историческая и социально- образовательная мысль. 2016.№ 6. С.106-109.

(c) Слонимский Денис Львович (sdlv2204@gmail.com). 